\title{
GUIDE TO ADEQUATE TREATMENT OF GONORRHOEA COMPLICATED BY STAPHYLOCOCCUS ALBUS*
}

\author{
BY \\ ROY L. TAWES, Jr. \\ 6044th USAF Dispensary, U.S. Forces, Korea ${ }^{\dagger}$
}

Gonorrhoea has always been considered of less interest and importance than syphilis, and because easily treated has received little attention. In the past 10 years physicians have reported cure rates of 95 to 98 per cent. in large series of patients with a single, conservative intra-muscular dose of penicillin (Fiumara, Appel, Hill, and Mescon, 1959; Norgaard, 1956). Recent textbooks and Armed Forces medical manuals likewise recommend this regimen on the basis of the marked susceptibility of $N$. gonorrhoeae to penicillin. However, during the past 6 years there have been increasing reports in the medical literature of failures with previously effective and greater doses of penicillin (Willcox, 1962; Reyn, Korner, and Bentzon, 1958; Epstein, 1959; Thayer, Field, Magnuson, and Garson, 1957; Sabath and Kivlahan, 1961; Barile, Van Zee, and Yaguchi, 1959). This has led to a concept of emergence of "resistant" strains. Several investigators have documented this changing pattern of penicillin sensitivity of strains of gonococci in the United States, Europe, and the Far East (Barile and others, 1959; McCarthy, Wallmark, and Finland, 1961). Other authors have taken exception to this concept as the sole explanation and have pointed out that other factors foster these high failure rates (Sabath and Kivlahan, 1961; McCarthy and others, 1961; Gangarosa and Cary, 1960; Svihus, Lucero, Mikołajczyk, and Carter, 1961 ; Sanders, Pelczar, and Hoefling, 1962; Gentele, Lagerholm, and Lodin, 1960; Kjellander and Finland, 1963a; Personal communications with U.S. medical personnel in the Far East). In Korea, failure rates are said to run between 10 and 30 per cent. with penicillin dosages ten to thirty times greater than those effective in the past $(300,000 \mathrm{U}$. to $600,000 \mathrm{U}$. procaine penicillin G intramuscularly: Epstein, 1959; Sabath and Kivlahan, 1961; Sanders and others, 1962; Personal communications with U.S. medical personnel in the Far East).

* Received for publication December 12, 1965

† Present address: Department of Surgery, San Francisco Medical Center, San Francisco, California.
The present study was undertaken to investigate the factors responsible for the high failure rate, and to find methods to insure adequate therapy in the least possible time.

\section{Materials and Methods}

148 members of the U.S. Army and Air Force reporting to V.D. sick call during a 4-month period were studied. Clinical histories were taken, physical examinations and serological tests carried out, and a Gram stained smear of the discharge and/or urine was examined for the presence of extra- or intra-cellular Gram-negative diplococci morphologically typical of $N$. gonorrhoeae. In addition, exudate was cultured on three media: chocolate agar, blood agar, and thiobroth. The plates were then incubated at $37^{\circ} \mathrm{C}$., the chocolate and blood agars in a 10 per cent. $\mathrm{CO}_{2}$ jar. 24 hours later colonies typical of $N$. gonorrhoeae were selected for subculture, Gram staining, oxidase test, random fermentation tests, and culture and disk sensitivity studies. Simultaneously, a representative colony of organisms showing heavy growth (50 or more colonies) on these plates was subcultured for Gram staining, and culture and sensitivity studies. The original colonies from which the subculture was taken likewise were subjected to Gram staining and culture and sensitivity study. Gonococcal colonies requiring $30 \mu \mathrm{g}$. penicillin discs to suppress growth were labelled as "relatively resistant", and those requiring $5 \mu \mathrm{g}$. as "sensitive".

Meanwhile the patient was put on one of three penicillin regimens while awaiting the culture and sensitivity results:

(1) the majority received 750,000 units procaine penicillin $G$ intramuscularly twice daily for from 7 to 10 days.

(2) Another group received procaine penicillin $G$ in oil, 300,000 units intramuscularly four times a day for 5 days.

(3) A third group was put on a short-term regimen designed to give high blood and tissue levels of penicillin: procaine penicillin G 600,000 units and aqueous penicillin $G \quad 300,000$ units intramuscularly twice daily for 2 days (doses administered 3 hours apart). 
These groups were designated as regimens A, B, and C respectively, and were selected to represent long, intermediate, and short-term therapies (Table I).

TABLE I

PENICILLIN REGIMENS

\begin{tabular}{c|c|c|c}
\hline \multicolumn{1}{c|}{ Regimen } & Drug & Dose (units) & $\begin{array}{c}\text { No. } \\
\text { of } \\
\text { Days }\end{array}$ \\
\hline A (long-term) & Procaine penicillin G & $\begin{array}{c}750,000 \\
\text { intramuscularly } \\
\text { twice daily }\end{array}$ & $7-10$ \\
\hline B (intermediate) & Penicillin G in Oil & $\begin{array}{c}300,000 \\
\text { intramuscularly } \\
\text { four times a day }\end{array}$ & 5 \\
\hline C (short-term) & Procaine penicillin G & $\begin{array}{c}600,000 \\
300,000 \\
\text { intramuscularly } \\
\text { twice daily* }\end{array}$ & 2 \\
\hline
\end{tabular}

Patients were instructed to return for laboratory followup studies (routine as above) $\mathbf{4 8}$ hours and 10 days after their last medication. All men were placed on medical restriction to their bases until cleared by the Dispensary. Cases were considered failures if symptomatic after treatment, or if evidence of $N$. gonorrhoeae was found on laboratory follow-up.

\section{Results}

On the basis of disc sensitivity findings in the original cultures and subcultures, four distinct groups in relation to penicillin sensitivity became apparent. These are represented in Table II as:

(1) Pure gonococcal infection.

(2) Gonococcal plus Staph. albus infection.
(3) "Apparently resistant" gonococci plus Staph. albus.

(4) "Relatively resistant" gonococci plus Staph. albus.

Note that in this study gonococcal organisms were considered relatively resistant to penicillin if $30 \mu \mathrm{g}$. disks (or greater concentrations) were necessary to suppress colony growth of the isolated $N$. gonorrhoeae.

It is worth noting that only 38 of the 148 men (26 per cent.) (Group I) presenting clinically as cases of gonorrhoea, represented "pure gonorrhoea" without the accompaniment of Staphylococcus albus (epidermidis) (Table II). In this group of 38 men, only one showed "high resistance" with penicillin disks ineffective in both high $(30 \mu \mathrm{g}$.) and low $(5 \mu \mathrm{g}$.) concentration, while three others showed relative resistance, being sensitive only to the $30 \mu \mathrm{g}$. disk.

In Group II gonococcal organișms were also quite sensitive to both penicillin disks while in the presence of Staph. albus.

However, in Group III, "apparently resistant", only the higher concentration $(30 \mu \mathrm{g}$.) penicillin disk was effective in suppressing colony growth with Staph. albus concomitants present, but when subcultured both penicillin ( 5 and $30 \mu \mathrm{g}$.) disks became effective in suppressing growth of the isolated $N$. gonorrhoeae.

In Group IV, "relatively resistant", both penicillin disks were ineffective in the presence of Staph. albus colonies on the plate, but when subcultured about half (16) of the $N$. gonorrhoeae

TABLE II

CLINICAL CORRELATION OF DISK SENSITIVITY AND FAILURE RATES

\begin{tabular}{|c|c|c|c|c|c|c|c|c|c|}
\hline \multirow{2}{*}{ Infection Group } & \multirow{2}{*}{ Regimen } & \multicolumn{3}{|c|}{$\begin{array}{c}\text { PCN Disc } \\
\text { Sensitivity ( } \mu \mathrm{g} .)\end{array}$} & \multirow{2}{*}{ Cases Treated } & \multicolumn{2}{|c|}{ No. of Failures } & \multicolumn{2}{|c|}{ Failure Rate (per cent.) $\ddagger$} \\
\hline & & 5 & 30 & $>30$ & & $\begin{array}{l}\text { Based on } \\
\text { Symptoms }\end{array}$ & Attributed to & Apparent & Corrected \\
\hline \multirow[t]{2}{*}{ I. Pure Gonococcus } & $\begin{array}{l}\mathbf{A} \\
\mathbf{B} \\
\mathbf{C}\end{array}$ & $\begin{array}{l}10 \\
13 \\
11\end{array}$ & $\begin{array}{l}1 \\
1 \\
1\end{array}$ & $\frac{1}{-}$ & $\begin{array}{l}12 \\
14 \\
12\end{array}$ & $\begin{array}{l}2 \\
1 \\
0\end{array}$ & $\begin{array}{l}2 \\
1 \\
0\end{array}$ & \multirow[t]{2}{*}{$\begin{array}{r}16 \cdot 7 \\
7 \cdot 1 \\
0 \cdot 0\end{array}$} & \multirow[t]{2}{*}{$\begin{array}{r}16 \cdot 7 \\
7 \cdot 1 \\
0.0\end{array}$} \\
\hline & Total & & & & 38 & 3 & 3 & & \\
\hline \multirow[t]{2}{*}{$\begin{array}{l}\text { II. Gonococcus and Staph. } \\
\text { albus }\end{array}$} & $\begin{array}{l}\mathbf{A} \\
\mathbf{B} \\
\mathbf{C}\end{array}$ & $\begin{array}{r}40 \\
7 \\
4\end{array}$ & $\begin{array}{l}\mathbf{0} \\
\mathbf{0} \\
\mathbf{0}\end{array}$ & 三 & $\begin{array}{r}40 \\
7 \\
4\end{array}$ & $\begin{array}{l}6 \\
1 \\
1\end{array}$ & $\begin{array}{l}1 \\
0 \\
0\end{array}$ & \multirow[t]{2}{*}{$\begin{array}{l}15 \cdot 0 \\
14 \cdot 3 \\
25 \cdot 0\end{array}$} & \multirow[t]{2}{*}{$\begin{array}{l}2 \cdot 5 \\
0 \cdot 0 \\
0 \cdot 9\end{array}$} \\
\hline & Total & & & & 51 & 8 & 1 & & \\
\hline \multirow[t]{2}{*}{$\begin{array}{l}\text { III. "Apparently Resistant" } \\
\text { Gonococcus and Staph. } \\
\text { albus* }\end{array}$} & $\begin{array}{l}\mathbf{A} \\
\mathbf{B} \\
\mathbf{C}\end{array}$ & $\begin{array}{l}\mathbf{0} \\
0 \\
0\end{array}$ & $\begin{array}{r}19 \\
5 \\
4\end{array}$ & $\bar{z}$ & $\begin{array}{r}19 \\
5 \\
4\end{array}$ & $\begin{array}{l}5 \\
2 \\
2\end{array}$ & $\begin{array}{l}2 \\
0 \\
0\end{array}$ & \multirow[t]{2}{*}{$\begin{array}{l}25 \cdot 8 \\
40 \cdot 0 \\
50 \cdot 0\end{array}$} & \multirow[t]{2}{*}{$\begin{array}{r}10 \cdot 6 \\
0 \cdot 0 \\
0 \cdot 0\end{array}$} \\
\hline & Total & & & & 28 & 9 & 2 & & \\
\hline \multirow[t]{2}{*}{$\begin{array}{l}\text { IV. "Relatively Resistant" } \\
\text { Gonococcus and Staph. } \\
\text { albust }\end{array}$} & $\begin{array}{l}\mathbf{A} \\
\mathbf{B} \\
\mathbf{C}\end{array}$ & $\begin{array}{r}14 \\
1 \\
1\end{array}$ & $\begin{array}{l}6 \\
3 \\
1\end{array}$ & $\begin{array}{l}5 \\
0 \\
0\end{array}$ & $\begin{array}{r}25 \\
4 \\
2\end{array}$ & $\begin{array}{r}12 \\
4 \\
1\end{array}$ & $\begin{array}{l}9 \\
2 \\
0\end{array}$ & \multirow[t]{2}{*}{$\begin{array}{r}48 \cdot 0 \\
100 \cdot 0 \\
50 \cdot 0\end{array}$} & \multirow[t]{2}{*}{$\begin{array}{r}36.0 \\
50 \cdot 0 \\
0.0\end{array}$} \\
\hline & Total & 16 & 10 & 5 & 31 & 17 & 11 & & \\
\hline
\end{tabular}

* NOTE: Subculture Results: All gonococci sensitive to $5 \mu \mathrm{g}$. when isolated, but apparently resistant with Staph. albus concomitants on the original culture plate, requiring $30 \mu \mathrm{g}$. to suppress growth.

$\dagger$ Subculture results given only. All gonococci were relatively resistant in the presence of Staph. albus.

$\ddagger$ See text for explanation. 
isolates revealed susceptibility to penicillin $(5 \mu \mathrm{g}$. disk) (Table II). The fifteen remaining isolates in Group IV exhibited a high degree of relative resistance to the two penicillin disks employed, requiring $30 \mathrm{mcg}$. or more to suppress colony growth. findings with the clinical failure rates on the three penicillin regimens. For example, considering only the long-term regimen A (96 patients), the overall failure rate was 26 per cent. if symptomatology alone was taken as the criterion (Table III). Despite treatment, many of these patients complained of a persistent clear watery discharge, occasionally thick in character, associated with dysuria and frequency of urination. However, further laboratory study revealed that gonorrhoea was responsible for only about 60 per cent. of these failures, while Staph. albus was apparently accounting for the symptoms in the remainder. Therefore, from the academic standpoint, the failure rate was 14.8 per cent. (gonorrhoea), while from the patient's standpoint it was 26 per cent. (gonorrhoea plus Staph. albus). These are expressed as "corrected" and "apparent" failure rates respectively in Tables II and III.

Of high significance is the observation that, as the penicillin disk sensitivity decreased, the penicillin effectiveness in vivo decreased resulting in higher failure rates (Table IV). The higher failure rates Group IV in Table II also reflect this observation. Considering only the seventeen failures attributable to gonorrhoea, the failure rate jumps from 2.5 per cent. in Group II, to 10.6 per cent. in Group III, and to a total of 44 per cent. in Group IV (Table II).
Tables II and III correlate these laboratory

If Group IV is further broken down on the basis of subculture sensitivities to penicillin, further correlation with clinical failure rates can be considered (Table II). Of the eleven failures in this group, six were shown to have $N$. gonorrhoeae sensitive only to $30 \mu \mathrm{g}$. discs, and five required more than $30 \mu \mathrm{g}$. to suppress colony growth, exhibiting a high degree of relative resistance. The failure rates were 60 per cent. (six out of the ten patients sensitive only to $30 \mu \mathrm{g}$. disks), and 100 per cent. (all five patients requiring more than $30 \mu \mathrm{g}$.) respectively in these cases. Similar comparisons for the other two penicillin therapies can be found in Tables II and III.

An additional observation deserves mention at this time. Of the 37 failures based on symptoms, only seventeen could be shown by culture and sensitivity to be attributable to gonorrhoea. In the cases of these seventeen gonorrhoea treatment failures, follow-up culture and sensitivity confirmed the decreased penicillin disk sensitivity of the strains of gonococci, and in fourteen the continued presence of Staph. albus. The twenty apparent treatment failures associated with Staph. albus, referred to above, all showed no diminished penicillin disk sensitivity.

Table $\mathrm{V}$ shows the overall disk sensitivity results with other antibiotics, erythromycin being the most effective and chloramphenicol second in suppressing colony growth. Other antibiotics tested that had an effectiveness lower than 20 per cent. are not reported. The failures in this series were treated with the antibiotic specifically indicated, and their symptoms subsided within 7 to 10 days' treatment, with the exception of seven cases who were thought

TABLE III

COMPARISON OF FAILURE RATES ON THREE PENICILLIN REGIMENS

\begin{tabular}{|c|c|c|c|c|c|}
\hline Regimen & $\begin{array}{c}\text { No. of } \\
\text { Patients Treated }\end{array}$ & $\begin{array}{c}\text { No. of Failures } \\
\text { (Staph. albus and GC) }\end{array}$ & $\begin{array}{c}\text { Apparent Failure } \\
\text { Rate per cent. (based } \\
\text { on Symptomatology) }\end{array}$ & $\begin{array}{l}\text { No. of Failures } \\
\text { (GC only) }\end{array}$ & $\begin{array}{l}\text { Corrected Failure } \\
\text { Rate per cent. } \\
\text { (attributable to GC) }\end{array}$ \\
\hline $\begin{array}{l}\text { A/Proc. Pen G } \\
\text { B/Pcn G in Oil } \\
\text { C/Proc. and Aq. Pen }\end{array}$ & $\begin{array}{l}96 \\
30 \\
22\end{array}$ & $\begin{array}{r}25 \\
8 \\
4\end{array}$ & $\begin{array}{l}26 \cdot 0 \\
37 \cdot 5 \\
18 \cdot 0\end{array}$ & $\begin{array}{r}14 \\
3 \\
0\end{array}$ & $\begin{array}{r}14 \cdot 8 \\
10 \cdot 0 \\
0 \cdot 0\end{array}$ \\
\hline Overall Series & 148 & 37 & $25 \cdot 0$ & 17 & $11 \cdot 5$ \\
\hline
\end{tabular}

TABLE IV

CORRELATION OF DISK SENSITIVITY WITH GONOCOCCAL FAILURES*

\begin{tabular}{|c|c|c|c|}
\hline \multirow{2}{*}{$\begin{array}{l}\text { Penicillin Disk } \\
\text { Sensitivity ( } \mu \mathrm{g} .)\end{array}$} & \multirow{2}{*}{ Cases Treated } & \multicolumn{2}{|c|}{ Gonococcal Failures } \\
\hline & & No. & per cent. \\
\hline $\begin{array}{r}5 \\
30 \\
>30\end{array}$ & $\begin{array}{r}129 \\
13 \\
6\end{array}$ & $\begin{array}{l}2 \\
9 \\
6\end{array}$ & \multirow[t]{2}{*}{$\begin{array}{r}1.6 \\
69.9 \\
100.0\end{array}$} \\
\hline Total & 148 & 17 & \\
\hline
\end{tabular}

Average (Expected per cent. Failures) $=11 \cdot 5$ per cent. Statistical Evaluation:

$\chi^{2}-96 \cdot 2 ; n=1 ; \mathrm{P}-0 \cdot 001$ (Highly significant).
* Considering all three penicillin regimens together.
TABLE V

DISK SENSITIVITY RESULTS COMPARISON OF PENICILLIN WITH OTHER ANTIBIOTICS (per cent.)

\begin{tabular}{cc|c|c}
\hline \multirow{2}{*}{ Antibiotic } & & \multicolumn{2}{|c}{ Isolates on Subculture } \\
\cline { 3 - 4 } & & N. gonorrhoeae & Staph. albus \\
\hline Penicillin & $\ldots$ & 77 & 47 \\
Erythromycin & $\ldots$ & 77 & 75 \\
Chloramphenicol & $\ldots$ & 78 & 70 \\
Tetracycline & $\ldots$ & 46 & 32 \\
Chlortetracycline & $\ldots$ & 45 & 36 \\
\hline
\end{tabular}


to have subacute prostatitis. The laboratory followup confirmed the impression of clinical cure.

Digital examination of the prostate of the 37 failures revealed a soft, boggy, somewhat enlarged organ (grade I) in seven cases. There were no symptoms referable to prostatitis in these patients; however, subacute prostatitis could not be ruled out. Three of these seven failures had gonorrhoea on follow-up, four had Staph. albus. On digital examination 3 to 4 weeks later, after further specific antibiotic treatment as indicated by culture and sensitivity, the prostate showed marked improvement or was within normal limits. Laboratory results corroborated these findings.

An incidental finding in this study was that of sixteen cases presenting with a history of recent sexual exposure, and complaining of a discharge ranging from clear watery to a yellowish mucous, burning, and frequency of urination. All had pyuria (too numerous to count/WBC/hpf), and Gram-positive cocci upon staining. Staph. albus was cultured in all sixteen cases. Sensitivity results revealed penicillin susceptibility in only two.

Another incidental finding in the study was that of asymptomatic 2 to $3 \mathrm{~mm}$. vesicular penile lesions in six cases. The lesions were shown to contain $N$. gonorrhoeae by culture, oxidase, and fermentation studies. Examples are shown in the Plate (opposite).

\section{Discussion}

\section{Factors Contributing to the Failure Rate}

The role of concomitant penicillinase-producing organisms, such as Staph. albus (epidermidis), in apparently protecting gonococci from the action of penicillin has been discussed elsewhere (Sanders and others, 1962; Gentele and others, 1960; Kjellander and Finland, 1963a). The complication of gonorrhoea by Staph. albus appears to be the rule in Korea, supported by the findings of 75 per cent. of the cases in this study. The combined factors of decreased penicillin susceptibility of certain strains of $N$. gonorrhoeae and the influence of penicillinaseproducing organisms, such as Staph. albus would appear responsible for the high failure rate with doses of penicillin up to 50 times those usually effective. However, the relative resistance of the strains of $N$. gonorrhoeae to penicillin is of prime importance. Statistical evaluation substantiates this (Tables IV, VI, and VII). In examining the significance of the role of Staph. albus a major assumption has been made-that those organisms resistant to penicillin were producing penicillinase. No laboratory procedures were available to prove this. This assumption would account for the apparent resistance of these organisms as well as the gonococci in the original cultures of Groups III and

TABLE VI

RESULTS OF PENICILLIN THERAPY * IN RELATION TO OCCURRENCE OF STAPH. ALBUS

\begin{tabular}{|c|c|c|c|c|c|}
\hline \multirow{3}{*}{\multicolumn{2}{|c|}{ Staph. albus }} & & \multicolumn{3}{|c|}{ Cases Treated } \\
\hline & & & \multirow{2}{*}{ Total No. } & \multicolumn{2}{|c|}{ Gonococcal Failures } \\
\hline & & & & No. & Per cent. \\
\hline $\begin{array}{l}\text { Prescnt } \\
\text { Absent }\end{array}$ & $\cdots$ & $\ddot{0}$ & $\begin{array}{r}110 \\
38\end{array}$ & $\begin{array}{r}14 \\
3\end{array}$ & $\begin{array}{r}12 \cdot 7 \\
7.9\end{array}$ \\
\hline Total & . & . & 148 & 17 & $11 \cdot 5$ \\
\hline
\end{tabular}

Average (Expected per cent. Failures) $=11 \cdot 5$ per cent.

Statistical Evaluation:

$\chi^{2}=0.52 ; n=1 ; 0.3<P<0.5$

* Considering all three penicillin regimens together.

TABLE VII

COMBINED EFFECT OF PENICILLIN SENSITIVITY OF GONOCOCCI AND OCCURRENCE OF STAPH. ALBUS ON RESULTS OF PENICILLIN TREATMENT OF GONORRHOEA

\begin{tabular}{|c|c|c|c|c|c|}
\hline \multirow{3}{*}{$\begin{array}{l}\text { Penicillin Disc } \\
\text { Sensitivity ( } \mu \text { g.) }\end{array}$} & \multirow{3}{*}{ Group } & \multirow{3}{*}{ Staph. albus } & \multicolumn{3}{|c|}{ Cases Treated } \\
\hline & & & \multirow{2}{*}{ Total No. } & \multicolumn{2}{|c|}{ Failures } \\
\hline & & & & No. & Per cent. \\
\hline \multirow[t]{2}{*}{5} & $\underset{\mathbf{B}}{\mathbf{A}}$ & $\begin{array}{l}\text { Absent } \\
\text { Present }\end{array}$ & $\begin{array}{l}34 \\
95\end{array}$ & $\begin{array}{l}\mathbf{0} \\
\mathbf{3}\end{array}$ & $\begin{array}{l}0 \\
3 \cdot 2\end{array}$ \\
\hline & Totals & & 129 & 3 & $2 \cdot 3$ \\
\hline \multirow[t]{2}{*}{ (and ${ }^{30}>30$ ) } & $\begin{array}{l}\text { C } \\
\text { D }\end{array}$ & $\begin{array}{l}\text { Absent } \\
\text { Present }\end{array}$ & $\begin{array}{r}4 \\
15\end{array}$ & 11 & $\begin{array}{l}75 \\
73\end{array}$ \\
\hline & Total & & 19 & 14 & 74 \\
\hline
\end{tabular}

Statistical Evaluation:

$\begin{array}{ll}\text { A v. B } & \chi^{2}=1.6 ; n=1 ; 0.1<\mathrm{P}<0.2 \\ \text { C v. D } & \chi^{2}=0.002 ; n=1 ; 0.98<\mathrm{P}<0.95 \\ \text { A v. C } & \chi^{2}=17.6 ; n=1 ; \mathrm{P}<0.001 \\ \text { B. } v . \mathrm{D} & \chi^{2}=62 ; n=1 ; \mathrm{P}<0.001\end{array}$ 

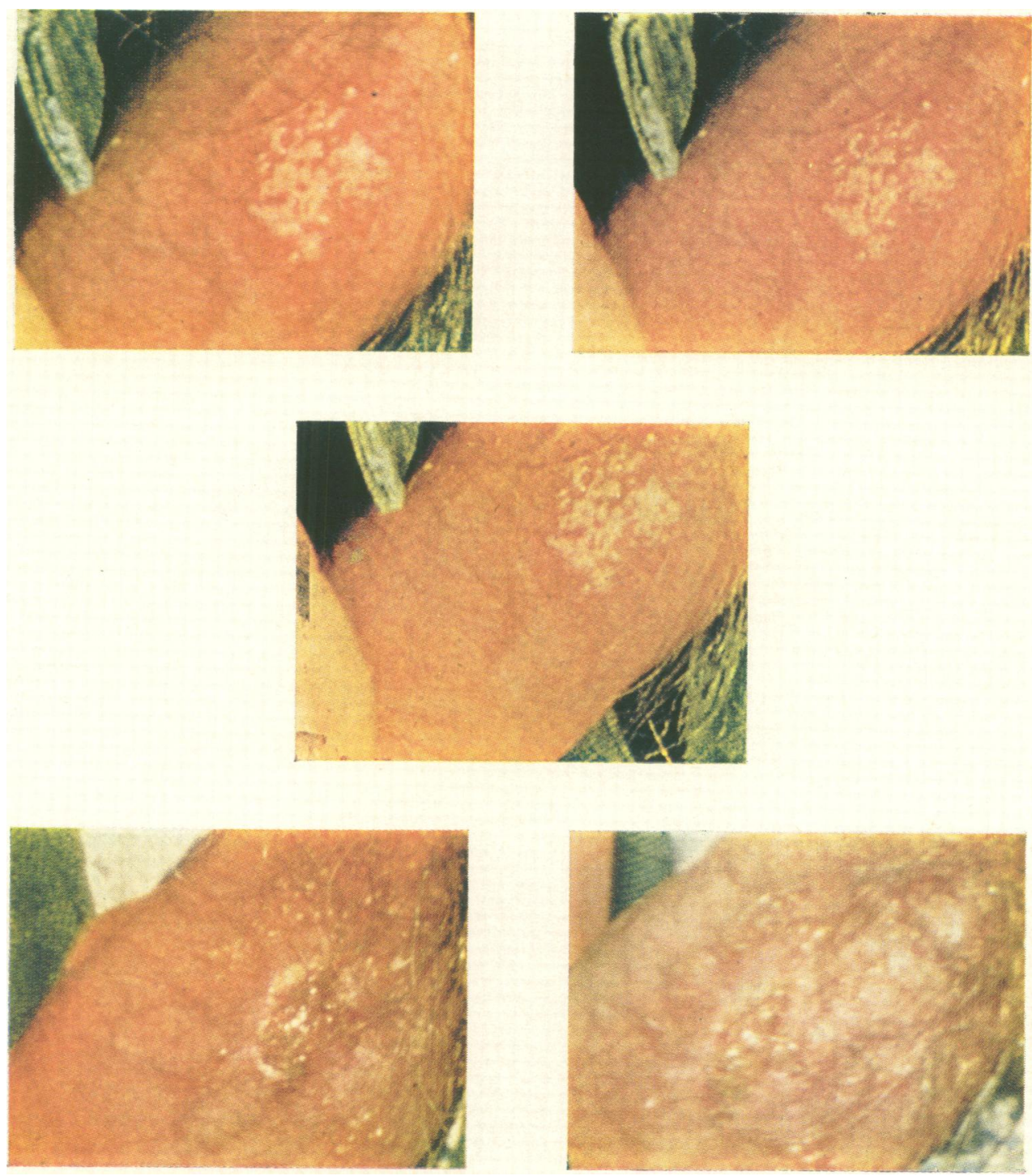

Plate.-Examples of vesicular penile lesions. 
IV (Table II). In these groups, before subculture isolates revealed gonococcal susceptibility to penicillin, it was impossible to determine whether relative resistance to penicillin could be attributed to less susceptible strains of $N$. gonorrhoeae or to interference by penicillinase from the concomitant Staph. albus on the culture plate. Conversely, if subcultures revealed the $N$. gonorrhoeae to be quite sensitive to penicillin, then it is logical to assume that the concomitant Staph. albus organisms were producing penicillinase in the original cultures of Groups III and IV, masking the sensitivity of the $N$. gonorrhoeae to penicillin. This in vitro interference with penicillin action by Staph. albus may presumably occur in vivo, contributing in part to therapeutic failures. However, in this respect it is not statistically significant, while the presence of relatively resistant strains of $N$. gonorrhoeae is highly significant statistically.

Tables IV, VI, and VII examine respectively the results of penicillin therapy in relation to disk sensitivity of the gonococci, occurrence of Staph. albus, and the combined effect of these two variables. In Table IV the difference in failure rates of the group with sensitive strains ( 1.6 per cent.) and the groups with relatively resistant strains $(69.9$ per cent. and 100 per cent.) is highly significant. Considering the difference in failure rates in relation to the occurrence of Staph. albus in Table VI, it is seen that the difference is not statistically significant between those with Staph. albus present $(12.7$ per cent.) and those with it absent ( 7.9 per cent.) In Table VII these observations are corroborated, as only the difference between relative sensitivities to penicillin is statistically significant in regard to the outcome of treatment (A versus $\mathrm{C}$ and $\mathrm{B}$ versus D), not the presence of Staph. albus. There were no failures in the 34 patients with sensitive gonococci, but eleven failures out of fifteen cases with relatively resistant gonococci (A versus C).

Sabath and Kivlahan (1961) stress a third factor in the importance of the proper penicillin regimen, one that attains a high blood and tissue level of penicillin over a 2- to 3-day period. Additionally, slow and irregular uptake of penicillin from the injection site has been demonstrated by Whittlesey and Hewitt, (1948), who found that over 60 per cent. of individuals receiving 600,000 units procaine penicillin $G$ failed to achieve a blood level as high as $\mathbf{0 . 3 2}$ units per ml. $(0.2 \mu \mathrm{g}$.$) at any time, and many even lower.$ McCarthy and others (1961), reported that the in vitro activity of various penicillins had to be in the range of 0.8 to $6.3 \mu \mathrm{g} . / \mathrm{ml}$. to suppress growth of $N$. gonorrhoeae. The success of the short-term penicillin regimen $\mathrm{C}$ in this study emphasizes this aspect of the treatment problem, as do the failures of long-term regimens $A$ and $B$.

A fourth factor involved in failures in this study is the possibility of a focus of infection in the prostate which intermittently seeded the genito-urinary tract with $N$. gonorrhoeae. Subacute prostatitis was suspected in seven of the 37 cases which failed to respond to treatment, a fact which supports this view.

A fifth factor hinges on the observation that Staph. albus (epidermidis) although commonly bacteria of extremely low virulence can cause disease; septicaemia and endocarditis have been reported. Kjellander and Finland (1963b) and Kjellander, Klein, and Finland (1963) have studied Staph. albus (epid.) extensively, and reported the penicillinase to be G. beta-lactamase. These authors have conclusively shown that, among 175 clinical isolates of Staph. albus, resistance to penicillin $\mathrm{G}$ was quite frequent ( 50 per cent.) as well as resistance to other antibiotics. The findings in this study support this observation. It is quite conceivable then that Staph. albus not only complicates treatment of gonorrhoea by interfering with the action of penicillin, but may itself play a pathogenic role. The findings of the 37 treatment failures seem to substantiate this view, as twenty symptomatic cases were found on follow-up to harbour not $N$. gonorrhoeae but Staph. albus. Verbal reports among physicians serving in Korea mention the fact that a non-specific urethritis frequently persists after the disappearance of gonococci following treatment. It is a tempting speculation that a great many of these cases of persistent urethritis may have been due to Staph. albus urethritis and/or subacute prostatitis. The incidental finding during this period of sixteen men from whom Staph. albus was cultured when they complained of discharges varying from clear watery to yellow mucous accompanied by frequent urination and dysuria, further suggests a pathogenic role of Staph. albus in the lower genito-urinary tract. Furthermore, this study demonstrates that, without conclusive laboratory evidence, the physician may clinically form the false impression on follow-up that the patient's persistent symptoms represent gonorrhoea. (Compare the apparent and corrected failure rates in Table II.) Conversely, a subclinical case of gonorrhoea may be passed off as one of non-specific urethritis, the patient then becoming a gonorrhoea carrier or going on to later complications. The fallibility of relying solely on Gram staining in the diagnosis of gonorrhoea has been pointed out by other workers (Svihus and others, 1961). Cultures are necessary to diagnose carriers with subclinical disease. 
A sixth factor involves the consideration that some of the resistant cases may have been due to some other Gram-negative intracellular diplococci. Gangarosa and Cary (1960) and Svihus have reviewed this problem and reported that organisms of the tribe Mimeae may cause a gonorrhoea-like syndrome as well as a Waterhouse-Friderichson syndrome. These organisms characteristically show high relative resistance to penicillin. Oxidase and fermentation tests have excluded these organisms in this study.

\section{Evaluation of Therapies}

Of the three penicillin regimens, one that attains a high blood level over a short period appears to be the most efficacious. A "four-shot", 2-day regimen is currently in use at this dispensary, but doses will be decreased until an optimal level of cures is attained over the shortest period. With this shortterm regimen of penicillin, there were no gonorrhoea failures in 22 patients studied, but in four symptomatic Staph. albus cases this regimen was of no value. An added advantage of this 2-day therapy is that specific antibiotics as indicated by culture and sensitivity may be substituted early in the treatment of the relatively resistant cases. Long-drawn-out repository penicillin regimens have been conclusively shown to be inadequate (Sabath and Kivlahan, 1961; Personal communication). In Korea, where "refractory" cases of gonorrhoea are common, some physicians have continued to increase doses of penicillin and to extend the period of treatment in quest of cures. The efficacy of this approach is dubious, as well as disconcerting to the patient. Regimen A demonstrates this point. Patients on Regimen A received 750,000 units procaine penicillin $G$ twice daily for 7 to 10 days. This regimen was reported to have shown a failure rate of greater than 20 per cent. and is fairly representative of military regimens employed in Korea (Personal communication). Consequently, it became a prime reason for the present investigation, which subsequently found this treatment to be the poorest of the three with an overall failure rate of 14.8 per cent. (Table III). Also, the physician should be aware that some cures may be more apparent than real (Tables II and III). This study illustrates that the patient's symptoms may be temporarily cured, but not his gonorrhoea; therefore, a subclinical case of decreased penicillin susceptibility persists, and is perpetuated in society by this iatrogenic carrier. King (1958) referred to this as an "infectious latency". Willcox (1958) suggested that the routine use of repository penicillin producing low tissue and blood levels may be significant in the development of relatively resistant $N$. gonorrhoeae.
The prostitutes and the promiscuous constitute a ready genetic pool for a Darwinian selection of the "fittest gonococci". It is readily understandable that the low tissue level attained by repository penicillin is conducive to the evolution of relatively resistant $N$. gonorrhoeae as well as of pathogenic Staph. albus. Therefore, it is an important public health and preventive medicine measure to eradicate infection from these carriers. The difficulty in diagnosing gonorrhoea in the female is well known, approximately 30 per cent. of subclinical cases being missed by common laboratory methods. This is not the case in the male, fortunately, and male carriers can be both diagnosed and cured.

\section{Comment}

The value of culture and sensitivity tests is selfevident, not only in delineating complicating factors responsible for high failure rates with penicillin, but as a guide to adequate treatment. In a series of 148 patients studied during a 4-month period, 110 (75 per cent.) had gonorrhoea complicated by Staph. albus (epid.) while seventeen (11.5 per cent.) harboured relatively resistant $N$. gonorrhoeae. Failure rates on different penicillin regimens were investigated and correlated with the culture and sensitivity findings. Susceptibility of the $N$. gonorrhoeae to penicillin was statistically a highly significant factor in attaining satisfactory treatment results. The role of presumably penicillinase-producing organisms was of no statistical significance. However, the question was raised as to the pathogenicity of Staph. albus in the lower genito-urinary tract. Also, the importance of subacute prostatitis, and of attaining high levels of blood penicillin over a short duration was cited. The necessity of prompt and adequate treatment to avert complications and to eliminate subclinical carriers of gonorrhoea was stressed. All cases in this series were clinically cleared from restriction to base only with substantial laboratory evidence that they were no longer infected. Specific antibiotic therapy, as indicated by culture and sensitivity tests, was instituted in all penicillin failures with satisfactory results.

The relative effectiveness of various antibiotics in vitro is presented in Table $\mathrm{V}$ as a guide for the treatment of penicillin failures. Reliance on a shortterm, high-dose penicillin regimen reinforced by culture and sensitivity results ensures adequate therapy in the minimum of time to patient and physicians. The effort and expense is justified in an area where failure rates are as high as in Korea.

\section{Summary}

Physicians serving in the U.S. Forces in Korea have encountered a high incidence of gonorrhoea 
refractive to intramuscular penicillin in dosages generally considered to be more than adequate. The purpose of this study was to investigate this observation and to delineate some of the responsible factors in the hope of attaining an adequate therapy. 148 men were studied over a 4-month period. 37 ( 25 per cent.) were treatment failures on the basis of symptoms, but only seventeen of these failures (11.5 per cent.) could be proven by culture studies to harbour $N$. gonorrhoeae, while the remainder harboured Staphylococcus albus (epidermidis). Culture and sensitivity studies correlated these seventeen gonococcal treatment failures with relatively resistant strains, and guided therapy with a specific antibiotic. Additionally, three penicillin regimens were evaluated. It was found that the regimen attaining a high blood level was the most efficacious. While the role of presumptively penicillinase-producing concomitants (Staph. albus) was examined and found to be of no statistical significance in the high failure rates, there was some question of the possible pathogenicity of Staph. albus in the genito-urinary tract.

\section{REFERENCES}

Barile, M. F., Van Zee, G. K., and Yaguchi, R. (1959). Antibiot. Med., Brit. Ed., 6, 470.

Epstein, E. (1959). J. Amer. med. Ass., 169, 1055.

Fiumara, N. J., Appel, B., Hill, W., and Mescon, H. (1959). New Engl. J. Med., $260,917$.

Gangarosa, E. J., and Cary, S. G. (1960). J. Amer. med. Ass., 173, 1808.

Gentele, H., Lagerholm, B., and Lodin, A. (1960). Acta derm.-venereol. (Stockh.), 40, 256.

Kjellander, J. O., and Finland, M. (1963a). New Engl. J. Med., 269, 834.

- , (1963b). Proc. Soc. exp. Biol. (N.Y.), 113, 1031.

- Klein, J. O., and Finland, M. (1963). Ibid., 113, 1023.

King, A. J. (1958). Lancet, 1, 651.

McCarthy, C. G., Wallmark, G., and Finland, M. (1961). Amer. J. med. Sci., 241, 143.

Norgaard, O. (1956). Acta derm.-venereol. (Stockh.), 36, 150.
Reyn, A., Korner, B., and Bentzon, M. W. (1958). Brit. J. vener. Dis., 34, 227.

Sabath, L. D., and Kivlahan, J. J. (1961). Amer. J. med. Sci., 242, 663.

Sanders, A. C., Pelczar, M. J. Jr., and Hoefling, A. F. (1962). Antibiot. and Chemother., 12, 10.

Svihus, R. H., Lucero, E. M., Mikołajczyk, R. J., and Carter, E. E. (1961). J. Amer. med. Ass., 177, 121.

Thayer, J. D., Field, F. W., Magnuson, H. J., and Garson, W. (1957). Antibiot. and Chemother., 7, 306.

Whittlesey, P., and Hewitt, W. L. (1948). Proc. Soc. exp. Biol. (N.Y.), 68, 658.

Willcox, R. R. (1958). Bull. Wld Hlth Org., 19, 503. (1962). Bull. Hyg. (Lond.), 37, 669.

Les directives à suivre pour le traitement adéquat de la blennorragie compliquée par le Staphylococcus albus

\section{RÉSUMÉ}

Les médecins des forces armées des États-Unis en Corée ont rencontré un taux élevé de blennorragie réfractaire à la pénicilline intra-musculaire en dosage généralement considéré comme étant plus qu'adéquat. Le but de cette étude était de faire une enquête au sujet de cette observation et de nommer les facteurs responsables dans l'espoir d'arriver à un traitement adéquat. 148 combattants ont été étudiés pendant une période de quatre mois. $37(25 \%)$ n'ont pas été guéris par le traitement en se basant sur les symptômes; la présénce de $N$. gonorrhoeae n'a été prouvée que par culture chez seulement $17(11,5 \%)$ d'entre eux, chez les autres des Staphylococcus albus (epidermidis) ont été trouvés. Des études de culture et de sensibilité ont montré que les 17 cas réfractaires au traitement étaient causés par des souches relativement résistantes et ont guidé le traitement vers un antibiotique spécifique. De plus trois dosages de pénicilline ont été évalués. On a trouvé que le dosage donnant un taux sanguin élévé était le plus efficace. Tandis que le rôle des concomitants (Staph. albus) produisant possiblement la pénicillinase a été examiné et trouvé sans signification pour les statistiques malgré le taux élevé des cas non-guéris, il a été un peu question de la pathogénicité du Staph. albus dans les voies génito-urinaires. 